\title{
Reaching all in rural sanitation: Experiences from inclusive programming in five countries
}

\author{
Naomi Carrard, ${ }^{1}$ Jeremy Kohlitz, ${ }^{1}$ Simone Soeters, ${ }^{1}$ Gabrielle Halcrow, ${ }^{2}$ Janina Murta, ${ }^{1}$ Juliet \\ Willetts $^{1}$ \\ ${ }^{1}$ Institute for Sustainable Futures, University of Technology Sydney \\ ${ }^{2}$ SNV Netherlands Development Organisation \\ Corresponding author: Naomi.Carrard@uts.edu.au
}

Keywords: Rural sanitation, inclusion, equality, human right to sanitation, local government, civil society

\begin{abstract}
There is a need to reflect on approaches to reaching all in rural sanitation, given evidence that disadvantaged groups often miss out on benefits from programs. This paper presents approaches from area-wide rural sanitation programming undertaken by SNV across five countries. Analysis identified ten strategies used in combination to support inclusion. We describe the strategies and their application, then present four implications for the rural sanitation sector: the value of a 'toolbox' approach; co-creation of strategies with stakeholders; recognition of local government as a driver of inclusive services; and the need to strengthen evidence on how strategies contribute to success.
\end{abstract}

\section{Introduction}

Research and practical experience on how rural sanitation programs can achieve equitable outcomes, and leave no one behind, is much needed. It is estimated that 2 billion people, the majority of whom reside in rural areas of developing countries, lack basic sanitation service (WHO and UNICEF 2019). The global water, sanitation and hygiene (WASH) sector is seeking to address inequalities in service delivery, with a strong mandate established by Sustainable Development Goal (SDG) target 6.2: "By 2030, achieve access to adequate and equitable sanitation and hygiene for all and end open defecation, paying special attention to the needs of women and girls and those in vulnerable situations" [emphasis added] (UN 2015). In order to achieve universal sanitation, concerted attention must be given toward disadvantaged individuals and groups who are often more difficult to reach. Disadvantaged individuals and groups, using the terminology recommended in the Human Rights to Water and Sanitation Handbook (de Albuquerque 2014), are people who may be discriminated against, experience inequalities, or are otherwise vulnerable or stigmatised. People may be disadvantaged due to poverty, physical or mental health challenges, limited social capital, geographical challenges, and marginalisation, discrimination and powerlessness (House, Cavill and Ferron, 2017). There are people in every context that struggle more than others to participate and be able to build, access, use and maintain sanitation facilities (House, Cavill and Ferron, 2017).

Sector monitoring reveals major disparities in sanitation access across different social groups. In 2017 basic service coverage among the richest quintile was at least twice as high as coverage among the poorest quintile in 48 out of 90 countries with disaggregated sanitation coverage data (WHO and UNICEF 2019). Emerging evidence indicates that other disadvantaged groups are also being left behind, with seven out of ten people who lacked basic services residing in rural areas in 2017 (WHO and UNICEF 2019; Slaymaker 2019). Inequalities emerge when disadvantaged individuals and 
groups are either intentionally excluded or treated less favourably by law, policy or practice, or unintentionally excluded because service provision fails to adequately account for their different needs (UN-Water 2015). Adjustments to relevant policies and practices are critically needed to ensure that disadvantaged individuals and groups receive the same beneficial sanitation outcomes as other groups, and that gaps in service delivery can be reduced rather than continued or augmented.

Three years since the SDG target was adopted, and as the sector ramps up efforts to realise its ambitions, it is timely to collate evidence to date on different approaches and their outcomes in order to systematically assess them, take stock of lessons learned, and build on successes. This paper contributes by presenting an analysis of SNV's Sustainable Sanitation and Hygiene for All (SSH4A) program and situating SNV initiatives with reference to literature on inclusive rural sanitation. SNV is a not-for-profit international organisation that works to improve the lives of people living in poverty by helping them raise incomes and access basic services in the agriculture, energy and WASH sectors. The SSH4A program has taken an intentionally inclusive approach to supporting sanitation access in 15 different countries. Through an analysis of experiences in five of those countries - Bhutan, Nepal, Cambodia, Zambia and Tanzania - this paper offers practical strategies and insights on how disadvantaged groups can be more centrally considered and reached through sanitation service delivery programs. These insights can usefully inform civil society and government in SNV partner countries, as well as the rural sanitation sector more broadly.

To situate the analysis, we begin by reviewing recent literature on reaching all in rural sanitation. We then provide an overview of the SSH4A program and present our approach to assessing inclusion activities across five countries. Findings from the study are described, detailing ten practical strategies for ensuring that sanitation programs reach disadvantaged individuals and groups. Finally, we discuss insights and implications arising from the study for SNV and the rural sanitation sector more widely.

\section{Common rural sanitation approaches and recent thinking on inclusion}

In this section, we discuss some of the limitations of common rural sanitation approaches in reaching disadvantaged individuals and groups, and the latest thinking on providing appropriate support. Rural sanitation programs typically blend different types of tools and methods, but predominant approaches to rural sanitation often fall into one of three categories: financing mechanisms, sanitation and hygiene behaviour change programs, or market and supply chain development (Venkataramanan, 2017). We consider the potential of each of these approaches to reach disadvantaged individuals and groups, then discuss recent conceptualising of what 'support' for disadvantaged individuals and groups entails.

\section{Financing approaches}

Financing approaches make use of financial instruments or services to either incentivise the provision of appropriate sanitation infrastructure and technologies, or make them more affordable for users. Early financing approaches to rural sanitation in the 1980s often fully-subsidised the construction of low-cost sanitation infrastructure (Rosenqvist et al. 2016). However, full subsidisation was often unsustainable, especially for poor user groups, for a variety of reasons including: failure to establish mechanisms for funding and incentivising operation and maintenance of the infrastructure; perceptions of subsidy capture and corruption; low levels of implementation capacity; scale limitations due to high costs; and failure to address demand and respond to user preferences (Jenkins and Sugden 2006; Jenkins and Scott 2007). 
Subsequent financing approaches aimed to only partially subsidise the cost of constructing, operating, or maintaining sanitation infrastructure with the remaining costs covered by users in order to create a sense of ownership. Literature describes the range of financial mechanisms, which are variously targeted at suppliers and consumers and include: connection subsidies; output-based subsidies and rebates; and regulatory advantages (for examples see Evans et al. 2009; Willetts 2013; Willetts and Powell 2016; Robinson and Gnilo 2016). Other financial mechanisms that have been used to support the procurement of sanitation hardware include upfront subsidies, subsidised credit schemes, loans offered by various local financial institutions, and community-based savings groups (Kwolek 2012; IDinsight 2013; Willetts and Powell 2016). Oftentimes, supportive agencies specifically target these mechanisms at low-income households by stipulating that only the poor, as defined by the government or the programme, are eligible to access them (Robinson and Gnilo 2016b).

However, financing approaches in general have a focus on affordability as a barrier, and are not often designed to address other barriers that disadvantaged individuals and groups face. Although affordability is frequently a major barrier to poor households gaining access to sanitation, other barriers such as lack of safety while accessing a toilet, requirements for appropriate technical designs or options suited to people with a disability, access to labour, lack of available land, social or political issues, and low demand for sanitation services can also be barriers. These barriers may require alternative forms of incentivisation and support, including non-financial approaches.

\section{Behaviour change approaches}

Behaviour change approaches aim to change social behaviours and practices relating to sanitation and hygiene. While these approaches typically focus at community scale and seek communal outcomes, such as open defecation free (ODF) status, research has found that such programs can at times fail to identify marginalisation and inadvertently exacerbate unequal power relations (House, Ferron and Cavill, 2017). For example, poor families and individuals in Nepal that were "triggered" by a behaviour change program to construct a latrine sold the only parcel of land they owned or became indebted to a cooperative in order to pay for the latrine (House, Ferron and Cavill, 2017, pg. 56).

There is increasing agreement in the literature that more explicit attention is needed on how behaviour change approaches affect disadvantaged individuals and groups. A salient example is Community-led Total Sanitation (CLTS), a mass mobilisation methodology that is perhaps the most prevalent behaviour change approach in the rural sanitation sector for eliminating open defecation. Research has found that despite its focus on collective outcomes, CLTS can be less effective for vulnerable groups, with disadvantaged households often the first to revert to open defecation in situations where follow up and support after a community declares open defecation free status is insufficient (Robinson and Gnilo 2016). It has also been argued that CLTS can shame, punish, and may cause psychosocial harm to predominantly poor people for circumstances beyond their control (Engel and Susilo 2014; Bateman and Engel 2018). Inequitable outcomes from CLTS may arise from a lack of attention to identifying who needs support, exclusion of disadvantaged individuals from triggering processes, weak intra-community support, low capacity of facilitators to respond to issues of inequality, or an absence of mechanisms to monitor inequalities (House, Cavill and Ferron 2017).

These experiences illustrate that realities and preferences of disadvantaged individuals and groups need to be explicitly considered if behaviour change approaches are to fulfil their ambitions of collective outcomes. Principles to support explicit consideration of inclusion have been developed 
(Myers et al. 2017; House et al. 2017), emphasising the importance of intentional engagement with potentially disadvantaged groups, monitoring and adapting programs to ensure inclusion, and seeking system level change that supports inclusion beyond the life of a single behaviour change program.

\section{Market and supply-chain approaches}

Market and supply-chain approaches utilise various methods but generally aim to use commercial techniques to raise supply and demand for sanitation products (Devine and Kullmann 2011). Businesses and entrepreneurs that market and provide sanitation products are typically the target actors of these approaches.

If not specifically designed to be inclusive, market and supply-chain approaches can also result in inequitable outcomes. Sanitation businesses may be guided by profit-maximisation and market efficiency (Venkataramanan 2017) which may lead them away from servicing poorer, less profitable customers (Gero et al. 2013). For example, empirical evidence in Indonesia and Vietnam demonstrates that poor households in rural and remote areas face higher costs for toilet construction which poses a barrier to household affordability and local business development (Willetts et al. 2017). Further, women are often underrepresented in sanitation enterprises and have less access to crucial financing resources than men (Leahy et al. 2017).

However, market and supply-chain approaches can be designed to promote pro-social business models. Civil society organisations (CSOs) have worked with sanitation suppliers to offer discounted products to poor customers and market products that are sensitive to the needs of people with disabilities (Triwahyudi and Setiawan 2014; Wei, May and Chowdhury 2016). A range of techniques can be used to support enterprises to reach disadvantaged users such as tax incentives for operating in remote and rural areas, development of low-cost sanitation technologies, and tailored support for female entrepreneurs (ISF-UTS 2016).

\section{A broad understanding of support}

Increasingly, efforts towards inclusive sanitation are integrating financial, behavioural and market approaches, with a broad definition of 'support' emerging that encompasses a variety of sources and forms of assistance at different scales (Willetts and Powell 2016; Myers et al. 2017; House et al. 2017). Forms of support include, but are not limited to, hardware-focused subsidies and technical assistance, software-focused institution building and behaviour change, and integration of these. Sources of support include family networks, the wider community, government (at different levels and from different sectors), the private sector, civil society organisations, or other development agencies. Myers et al (2017), with a focus on CLTS and related programmes, broadly categorise support mechanisms as either (i) facilitating and strengthening intra-community support; or (ii) providing assistance from outside a community. In this conceptualisation, support arising from within a community, for example, can come from a household sharing their land with their neighbour for construction of a latrine. External support may include advice or financial assistance from a government social welfare mechanism or development agency. This categorisation is helpful in that it prompts consideration of a broader set of potential support mechanisms than historically promoted, particularly at the community scale. Yet the critical role of local government as responsible for ensuring inclusive sanitation service delivery in line with the human right to sanitation (Keatman et al. 2016), as well as the range of ways in which interactions with private or social enterprise can be configured (ISF-UTS 2016), can be overlooked in a binary framing of community and external. 
It is nevertheless helpful to consider the scale of support, though taking a broad view of 'local' that encompasses both community processes as well as local (typically district-level) government and also non-government (private sector, civil society) activities. Localised forms of support are especially important for three reasons. First, local government is typically responsible for ensuring the sanitation needs of all rights holders are met, yet is often constrained by limited resources and authority (Keatman et al. 2016). Second, focusing initially on local pathways to support inclusive sanitation is the "least likely to disrupt and undermine community processes...the targeting is more likely to be accurate, and the level of support is more likely to be appropriate" (Myers et al. 2017) and can also promote engagement with locally-based entrepreneurs (Willetts et al. 2015). Finally, focusing on local support highlights the role of development agencies as facilitators rather than providers of inclusive sanitation. As part of such an approach, there is opportunity both in and through sanitation programmes to support local efforts to shape social dynamics around potential disadvantage towards greater acknowledgement of the particular preferences and needs of vulnerable groups, including people with disability and women and girls (e.g. Ahmed et al. 2011; Carrard et al. 2013).

\section{Background: Sustainable Sanitation and Hygiene for All}

Sustainable Sanitation and Hygiene for All (SSH4A) is a capacity building programme developed by SNV for delivering government-led sustainable sanitation services in rural areas of developing countries at scale. The programme has been developed since 2008 in Asia and has since expanded to 135 districts across 18 countries in Asia and Africa. Within each district, an area-wide approach is taken seeking to support government in achieving services for all across the whole district. SSH4A is guided by a shared framework comprising four complementary components: sanitation demand creation; sanitation supply chains and finance; hygiene behavioural change communication; and WASH governance, supported by a suite of learning activities and performance monitoring. SSH4A also advances rights-based approaches that focus on development of local capacities, scalability through government-led district-wide approaches to sanitation, and continual knowledge development and learning. Within the programme, significant autonomy is granted to individual country teams to tailor their approaches to specific contexts where the programme is being implemented. Reflecting this, the scale, phasing and duration of the SSH4A SNV programme varies across countries.

For a decade, the programme has been exploring and tailoring various approaches for gender and social inclusion (GESI). Relevant outcome indicators have been included in monitoring protocols since programme inception, and collective wisdom on practical strategies for increasing inclusion was codified in a set of guidelines in 2012 (following a learning event on the topic). The guidelines provide practical tips and entry points for staff and partners to address GESI within each of the four SSH4A components. The objective of mainstreaming GESI into SSH4A activities has been to ensure that both the practical needs and strategic interests (Molyneux 1985; Moser 1989) of disadvantaged individuals and groups are met. Since the mainstreaming of GESI into SSH4A, individual SNV country offices have piloted diverse strategies for reaching disadvantaged individuals and groups.

\section{Approach}

The study sought to articulate the breadth of inclusion strategies being implemented across SSH4A countries, and to facilitate critical reflection on the strengths and limitations of strategies with SNV teams. A qualitative desk-based approach was taken, involving phone/video interviews and document analysis. Five case study countries spanning South Asia (Nepal and Bhutan), South-east 
Asia (Cambodia) and Africa (Zambia and Tanzania) were chosen to represent both older and newer SSH4A programmes in diverse rural sanitation sectors. The research was conducted jointly by the Institute for Sustainable Futures at the University of Technology Sydney (ISF-UTS) and SNV in 2017-2018.

Data collection methods included: (i) review of literature on reaching all in inclusive sanitation; (ii) review of country programme documents including formative research reports, focused studies, relevant policy documentation and e-discussions on best practices; (iii) interviews with 17 SNV staff across the five countries, including follow up interviews to clarify details and confirm correct interpretation; (iv) initial findings from an analysis of SSH4A monitoring data from multiple countries undertaken by Emory University; and (iv) eliciting insights from an SNV learning event focused on reaching all in rural sanitation held in Lampung, Indonesia in May 2017 and attended by SNV staff and partners from eight SSH4A programme countries, including the five reviewed here.

Data from document reviews and interviews was collated and inductively analysed by two team members to identify common strategies employed across case study countries, the specific ways these were implemented and outcomes achieved (where available). Findings were documented then shared with SNV sector leaders for each case study country to confirm interpretations, with review and input also provided by Asian, African and global program leaders. Finally, findings were considered with reference to literature to generate insights for SNV and the rural sanitation sector more widely.

A limitation of the study was variability in data collected across case study countries, with some strategies documented in great detail (e.g. the use of subsidies in Cambodia) and others more implicit within program activities and reliant on the recall of program teams (e.g. integration of inclusion into government processes). Related to this, staff changes in both SNV and ISF-UTS teams limited the continuity of reflection and analysis for some strategies. These limitations were addressed by close involvement from regional program managers and follow up interviews when necessary.

Nevertheless, tracing details of all strategies, and how they were experienced, was a challenge.

\section{Findings: Strategies for reaching all in SSH4A}

Across the five country programmes, SNV teams used a variety of approaches for both identifying and reaching disadvantaged areas, individuals and groups. Identifying hard to reach and otherwise disadvantaged areas occurred prior to programme implementation and informed the selection of districts to partner with. In Bhutan, a process of assessment using 15 criteria (e.g. poverty, open defecation rates) was used to identify priority programme districts with the lead government agency. In Nepal and Cambodia areas with low service levels or high rates of open defecation were targeted (eg Terai in Nepal). In Tanzania, SNV focused on remote areas, learning from and extending the Government of Tanzania's National Sanitation Campaign. In Zambia, SSH4A was implemented in areas not receiving support from the large-scale DFID funded Zambia Sanitation and Hygiene Programme (ZSHP) implemented by the Government in partnership with UNICEF or any other donor programs.

During programme implementation, SNV country teams characterised the situation of disadvantaged groups within target districts. They worked with partners to develop an understanding of the local context and sanitation sector dynamics, which included exploring and assessing stakeholder perspectives and available data to identify groups or sub-districts that were disproportionally unserved. Identification of disadvantage was undertaken as an ongoing process, and throughout the 
implementation of programme activities SNV teams undertook focused research studies and collected disaggregated monitoring data to review progress and adapt activities in response.

\section{A toolbox of strategies}

Based on an evolving understanding of which groups may be experiencing disadvantage, SNV employed ten distinct support strategies across the case study countries. The strategies together represent a 'toolbox' or collection of strategies that can be selected, tailored and used as appropriate for different contexts. The strategies are summarised in Table 1 with a description of countries where each was applied and relevant target groups. Each country used a different combination of these strategies and focused them at different scales and groups (e.g. poor, women, or people living with disabilities). Identified strategies span behavioural or institutional $(n=8)$ and financial $(n=2)$ mechanisms, with a dominant focus on leveraging social relationships, strengthening governance, and incentivising pro-social behaviour. The diversity of strategies - which span social, financial, and political domains - responds to the complex and diverse realities faced by disadvantaged individuals and groups, and to the different levels of maturity of programmes and sectors in case study countries.

Table 1. Support strategies used across country programmes

\begin{tabular}{|l|l|l|}
\hline Strategy & Description & $\begin{array}{l}\text { Countries applied } \\
\text { (target } \\
\text { groups/considerations) }\end{array}$ \\
\hline $\begin{array}{l}\text { Develop local } \\
\text { leadership for } \\
\text { mobilising } \\
\text { collective } \\
\text { action }\end{array}$ & $\begin{array}{l}\text { Incentivise or motivate local leaders to pool resources } \\
\text { and labour from the local community in order to } \\
\text { assist disadvantaged households achieve sanitation } \\
\text { access, and to monitor progress }\end{array}$ & $\begin{array}{l}\text { All (vulnerable groups } \\
\text { in general) }\end{array}$ \\
\hline $\begin{array}{l}\text { Tailor social } \\
\text { mobilisation, } \\
\text { behaviour } \\
\text { change } \\
\text { communication, } \\
\text { and demand } \\
\text { creation } \\
\text { interventions to } \\
\text { local contexts } \\
\text { and groups }\end{array}$ & $\begin{array}{l}\text { Conduct formative research with different groups and } \\
\text { draw on local experience to customise social } \\
\text { mobilisation, behaviour change communication, and } \\
\text { demand creation interventions so they reflect the } \\
\text { needs and challenges of disadvantaged groups in } \\
\text { make use of existing support mechanisms }\end{array}$ & $\begin{array}{l}\text { All (ethnic minorities, } \\
\text { poor households, } \\
\text { women, children and } \\
\text { the elderly) }\end{array}$ \\
\hline $\begin{array}{l}\text { Encourage } \\
\text { inclusive and } \\
\text { pro-poor } \\
\text { sanitation } \\
\text { business } \\
\text { models }\end{array}$ & $\begin{array}{l}\text { Encourage business models that market affordable } \\
\text { products and services designed to meet the needs of } \\
\text { women and people living with disabilities, and } \\
\text { support people from disadvantaged groups to run } \\
\text { sanitation businesses }\end{array}$ & $\begin{array}{l}\text { All (women, people } \\
\text { with disabilities, poor } \\
\text { households) }\end{array}$ \\
\hline $\begin{array}{l}\text { Promote } \\
\text { inclusive } \\
\text { technologies }\end{array}$ & $\begin{array}{l}\text { Identify and promote locally appropriate sanitation } \\
\text { technologies that accommodate the needs of women } \\
\text { and people with disabilities, and support } \\
\text { implementers and masons to design and construct } \\
\text { these technologies }\end{array}$ & $\begin{array}{l}\text { Bhutan, Nepal, Zambia } \\
\text { and Tanzania (people } \\
\text { with disabilities, } \\
\text { women, elderly) }\end{array}$ \\
\hline
\end{tabular}




\begin{tabular}{|l|l|l|}
\hline $\begin{array}{l}\text { Integrate } \\
\text { inclusive } \\
\text { sanitation } \\
\text { processes into } \\
\text { government } \\
\text { planning and } \\
\text { budgeting }\end{array}$ & $\begin{array}{l}\text { Collaborate with government partners to integrate } \\
\text { mechanisms designed to support disadvantaged } \\
\text { groups into government guidelines, strategies, } \\
\text { programmes and budgets for sanitation, especially at } \\
\text { a local level }\end{array}$ & $\begin{array}{l}\text { All (poor households, } \\
\text { people with disabilities, } \\
\text { women) }\end{array}$ \\
\hline $\begin{array}{l}\text { Work with } \\
\text { rights holders } \\
\text { groups }\end{array}$ & $\begin{array}{l}\text { Engage civil society organisations, community } \\
\text { groups, and other organisations that specialise in } \\
\text { advocacy for disadvantaged groups during planning, } \\
\text { implementing, and monitoring of sanitation projects }\end{array}$ & $\begin{array}{l}\text { Nepal and Tanzania } \\
\text { (people with } \\
\text { disabilities, women) }\end{array}$ \\
\hline $\begin{array}{l}\text { Offer targeted } \\
\text { subsidies for } \\
\text { latrines }\end{array}$ & $\begin{array}{l}\text { Offer targeted discounts that cover part of the cost of } \\
\text { constructing, operating, or maintaining a latrine }\end{array}$ & $\begin{array}{l}\text { Cambodia (poor } \\
\text { households) }\end{array}$ \\
\hline $\begin{array}{l}\text { Support self- } \\
\text { financing } \\
\text { mechanisms }\end{array}$ & $\begin{array}{l}\text { Support mechanisms or programmes, such as savings } \\
\text { clubs, that enable households to pool resources } \\
\text { together to cover the upfront costs of latrines }\end{array}$ & $\begin{array}{l}\text { Zambia and Tanzania } \\
\text { (vulnerable groups in } \\
\text { general) }\end{array}$ \\
\hline $\begin{array}{l}\text { Evidence-based } \\
\text { advocacy }\end{array}$ & $\begin{array}{l}\text { Based on evidence produced through rigorous } \\
\text { research and knowledge sharing platforms, advocate } \\
\text { for and inform approaches for supporting } \\
\text { disadvantaged groups to access sanitation }\end{array}$ & $\begin{array}{l}\text { All (people with } \\
\text { disabilities, poor } \\
\text { households, female- } \\
\text { headed households) }\end{array}$ \\
\hline $\begin{array}{l}\text { Advocate for } \\
\text { non- } \\
\text { discriminatory } \\
\text { use of sanctions }\end{array}$ & $\begin{array}{l}\text { Work with local (district) governments and } \\
\text { community leaders to advocate for non- } \\
\text { discriminatory use of sanctions mandated by local by- } \\
\text { laws }\end{array}$ & $\begin{array}{l}\text { Nepal, Zambia and } \\
\text { ganzania (vulnerable }\end{array}$ \\
\hline
\end{tabular}

\section{The strategies in practice: illustrative examples}

This section presents examples of each of the strategies employed across case study countries. Examples presented represent a subset of all relevant activities reviewed as part of this study (see ISF-UTS and SNV 2018 for a more complete description). Those included here illustrate the diversity, ground the strategies with concrete examples and identify major issues or challenges faced in their implementation.

Across case study countries, programme teams partnered with local leaders to mobilise collective community action in support of inclusion. Incentive approaches were used in Nepal, including 'naming and praising' those who offered assistance (e.g. in the form of labour or land) during community events and ceremonies. In Zambia, material and financial incentives were offered to community champions to encourage an inclusive approach, including bicycles (to enable champions to visit households who may not have attended triggering) and cash rewards (USD10 for every ten ODF villages). These were a popular measure, though required careful management as they raised expectations of reward for others in voluntary roles. In Cambodia, Bhutan and Tanzania, regular district level meetings informed by monitoring data provided space for commune leaders to reflect on successes and failures, which promoted peer accountability and commitment to action. In Bhutan, the programme tapped into already existent traditional pro-poor support mechanisms which facilitated collective action (in the form of labour, materials or transport) to support disadvantaged households. 
SSH4A programme teams facilitated inclusion by tailoring social mobilisation, behaviour change communication (BCC) and demand creation activities to local contexts with government partners. In Nepal, a tailored mobilisation strategy for the Muslim minority population in Banke district was adopted. This involved a senior Muslim social mobiliser from the eastern part of the Terai being contracted to oversee and facilitate mobilisation activities, with a female Muslim social mobiliser also being employed to facilitate engagement with Muslim women. In Bhutan, the government's Community Development for Health $(\mathrm{CDH})$ tool was adapted to reach potentially vulnerable groups, which included adjusting CDH processes in terms of timing, venue selection and facilitation to ensure participation of women and the least vocal were assured. In each country programme, SNV undertook handwashing and sanitation behaviour studies to inform the BCC design which resulted in segmentation of the SSH4A BCC strategy into different target population groups (children, elderly, women and men) to promote inclusive sanitation programming.

Programme teams also promoted inclusive sanitation business and financing models. In Tanzania, for example, SNV trained Local Business Entrepreneurs (LBEs) in demand creation and construction of affordable and durable latrines for the poorest households. In Zambia, SNV worked with Sanitation Marketing Groups (SMGs) to mobilise collective village funds for the construction of household latrines. In Bhutan and Nepal, female entrepreneurship was promoted and supported including linking female business owners to rural consumers, women's groups and strengthening private sector capacity to supply desirable and affordable sanitation products and services for vulnerable groups, in particular women.

Across the case study countries, inclusive technologies were promoted including training masons on inclusive designs and supporting disadvantaged groups to make informed choices about sanitation facilities. In Nepal, Bhutan, Tanzania and Zambia, country programmes developed booklets, visual aids (for those with low literacy levels), and marketing materials with information about different toilet technologies and/or solutions for people with disabilities, households in challenging environments and options for different affordability levels. In Tanzania, portable wooden stools designed as pedestals for the elderly and people with disabilities to sit on while defecating were introduced to project districts, making the available squat toilets more accessible.

An approach employed across all of the SSH4A case study countries was to work towards institutionalisation and mainstreaming of inclusive sanitation into government planning and budgeting. In Bhutan, SNV (with national government partners) facilitated inception workshops that established sanitation and hygiene as agenda items in local assemblies, and worked with local health officials to advocate for prioritising, planning and budgeting for sanitation and hygiene activities within the local government. In Nepal, SNV was part of the multi-stakeholder process that led to the development of the national sanitation and hygiene plan based on the principles of access for all and engagement of all. As part of post-ODF efforts in Cambodia, the SSH4A programme built on established governance structures to set up a district sanitation committee as a sub-group of an existing multi-sector committee. SNV also worked with local government on the institution of postODF regulations and plans, and advocated for the allocation of commune budget for sanitation including particular support for poor households unable to afford a toilet. In Tanzania, SSH4A activities were aligned with and embedded into district level sanitation plans. With SNV support, the local government ensured that leaving no one behind principles were adhered to in the SSH4A districts, which involved targeting potentially vulnerable groups and ensuring planning and budgeting processes factored in strategies for supporting disadvantaged households. 
SSH4A programme teams also worked with rights holders' groups to promote inclusion. In Bhutan, SNV developed a relationship with Ability Bhutan, a Disabled People's Organisation (DPO) and women's groups including the Bhutanese Association of Women Entrepreneurs (BAOWE), and facilitated their involvement in multi-stakeholder processes supporting development of the National Sanitation and Hygiene Policy (RSAHP). In Nepal and Cambodia, SNV engaged DPOs in district level multi-stakeholder workshops and in Cambodia teams also facilitated Commune Committees for Women and Children (CCWC) to further engage in sanitation demand creation activities. In Tanzania, SSH4A teams attempted to involve women's groups and DPOs in program activities, however meaningful long-term engagement was hindered by a lack of formalized organizational structures.

In Cambodia, SNV piloted use of a latrine discount for poor households, administered by local government partners and using the established national government's poor identification system. The mechanism involved offering a time-bound discounted pour-flush latrine to poor household in communes that had already reached $80-100 \%$ sanitation coverage. The mechanism was successful in fast-tracking progress towards the country's first ODF district, though a review found the mechanism was not likely to be nationally scalable at a reasonable cost without significant improvements in institutional and human resource capacity at local government level (Murta et al. 2017).

In Zambia and Tanzania, the SSH4A programme established self-financing mechanisms to reduce costs for households and local entrepreneurs (as suppliers). In Zambia this involved setting up a community-based scheme whereby sanitation action groups mobilised financial resources from interested households. The money collected was used to negotiate bulk purchases of materials and services to construct toilets for up to ten households at a time at wholesale price. In Tanzania, SNV piloted a revolving fund for local entrepreneurs to increase their latrine production and income. This was initially successful, however after time local entrepreneurs stopped accessing the fund for fear of defaulting on the loan.

Across all of the case study countries, SHH4A programme teams undertook evidence-based advocacy based on monitoring data and research activities to promote more inclusive sanitation approaches. Across SSH4A countries, monitoring data informs reflection processes, advocacy strategies and program adjustments. The data is analysed with partners in sense-making workshops and used to design capacity building at different levels (community through to national). In Zambia and Tanzania for example, disaggregated monitoring data was made public and accessible to government and community stakeholders and used to advocate for a focus on disadvantaged groups. In Nepal, formative research and programme monitoring data was used to advocate at national level for appropriate WASH services for people with disabilities. In Bhutan, SNV conducted research at different points in time to inform dialogue with government stakeholders towards supporting more inclusive approaches. This included collaborative formative research that SNV undertook with the Ministry of Health and Ability Bhutan, the national Disabled People's Organisations to better understand the sanitation and hygiene situation of rural people with disabilities. Findings and recommendations from the research were disseminated at national and district levels with various stakeholders at different WASH forums. SNV drew on this research to inform and influence development of the National Sanitation and Hygiene Policy in 2017.

Finally, in three of the case study countries (Nepal, Tanzania and Zambia), where local sanitation strategies included the use of sanctions, SNV teams advocated for their appropriate and nondiscriminatory use. Strategies included establishing participatory processes to encourage 
compliance and reduce the need for sanction-based enforcement (in the form of fines or removal of social services), and working with community and government leaders to prioritise alternative demand-creation strategies rather than relying on sanctions as the primary tool to achieve ODF.

\section{Outcomes achieved}

Analysis of disaggregated monitoring data from eleven SSH4A countries including the five in this study indicated progress in reducing inequalities for the poor, people with disabilities, female headed households and older people (Garn et al. 2018). Most case study countries saw improvements over time for these groups across both access and use indicators, including a reduction in disparities between groups (indicating faster rates of progress for disadvantaged groups). Yet monitoring data also pointed to persistent challenges and unequal progress in some areas. For example, female headed households in Bhutan and households of people with disabilities in Zambia experienced slower rates of progress compared with other groups. The sustainability of equitable outcomes has been a challenge in Tanzania, where poor households initially gained access to toilets at a relatively high rate but then slipped back, with the basic facilities unable to withstand multiple rainy seasons. Within case study countries, findings from disaggregated monitoring data were used to tailor and adjust the next stages of SNV programming. However, it should be noted that country-level data focused on disadvantaged groups reflected small sample sizes. Disaggregated data on the effectiveness of support mechanisms in helping disadvantaged groups access safe sanitation are generally lacking across the global WASH sector (Kohlitz et al. 2019). Interpretation for particular country programme areas requires further consideration, as does identifying which support strategies were most effective for achieving those outcomes (discussed further below).

\section{Discussion}

Reflecting on findings from our review of SSH4A activities with reference to sector literature, we identify four implications for practice and programming, relevant for both SNV and the wider sanitation sector: (i) a toolbox approach to addressing disadvantage and reaching all allows tailoring of strategies as appropriate for different groups across diverse contexts; (ii) co-creation of strategies with local actors can drive a more systemic approach to inclusion; (iii) local government plays a pivotal role, and should be a focus of inclusive programming; and (iv) there is a need to strengthen evidence on the effectiveness of support strategies, which requires both clear articulation of desired outcomes and improved evaluation techniques.

\section{A toolbox approach to reaching all}

There is strength in diversity, with a 'toolbox' of adaptive strategies best able to address the varied needs of vulnerable groups in different contexts and at different stages of programming and sector development. While the SSH4A programmes were all united by a rights-based approach and a focus on strengthening government roles, individual countries did not follow a common 'best' strategy. Instead, they each trialled a range of activities tailored to local contexts. By approaching a situation with a toolbox of strategies that mixes different types and sources of support, context-specific or emergent challenges - which are common amongst marginalised people who live with relatively high instability - can be more adeptly handled than through a single prescribed strategy. Strategic timing of different support strategies is also critical because what works at one stage of programming might not work at another. Getting the right combination of strategies for a particular setting requires close monitoring and regular evaluation. A level of trialling and refining is needed to work out appropriate strategies and their timing, with safeguards put in place to ensure that unsuccessful trials do no harm (SNV 2019). 


\section{Co-creating strategies to embed an inclusive approach}

SSH4A experiences indicate that co-creation and multi-stakeholder work is key to delivering a range of strategies that drive more equitable outcomes. This requires a focus on embedding support and attention to reaching all within local institutions as well as market-based actors. SSH4A programme staff reflected that undertaking focused studies (to identify vulnerable groups and inform the design of support strategies) in collaboration with local government and civil society partners was a valuable way to generate insights that were then used. In working closely with government and civil society partners, collaboratively implemented research processes facilitated increased knowledge, engagement and political will for inclusive approaches.

There is also potential to expand the network of support beyond the usual sanitation stakeholders to tap existing social welfare systems, both formal and informal. Working with rights holder's organisations and/or with government may provide insight into existing support mechanisms for disadvantaged individuals and groups, including lessons learnt and opportunities to draw on these to advance sanitation. Beyond an instrumental approach, this speaks to a broader imperative to seek development pathways that address multiple SDGs (Nilsson et al. 2016).

\section{Recognising the pivotal role of local government}

Working closely with local government as the duty bearer to drive inclusion initiatives both builds capacity to deliver (or oversee) inclusive services and increases accountability for leaving no one behind. Local government typically has responsibility for overseeing sanitation service delivery and as such is the level where responsibility for realising the human right to sanitation lies (Keatman 2016, Pati and Neumeyer 2017). Working with (and at the scale of) local government has been a defining characteristic of SSH4A activities, as shown in Figure 1, which maps SSH4A strategies across households/community, local government/business and national scales. Across case study countries, SSH4A programme staff reflected that close engagement with local government was key to successful implementation of a range of strategies, from embedding inclusion principles in district level sanitation plans in Tanzania to administering a latrine discount for poor households in Cambodia. For the sector more widely, while emerging principles emphasise strengthening the enabling environment, the key role of local government could be more specifically considered in recognition of the vital role of local government in scaling up social and public health programs (Venkataramanan 2016). 


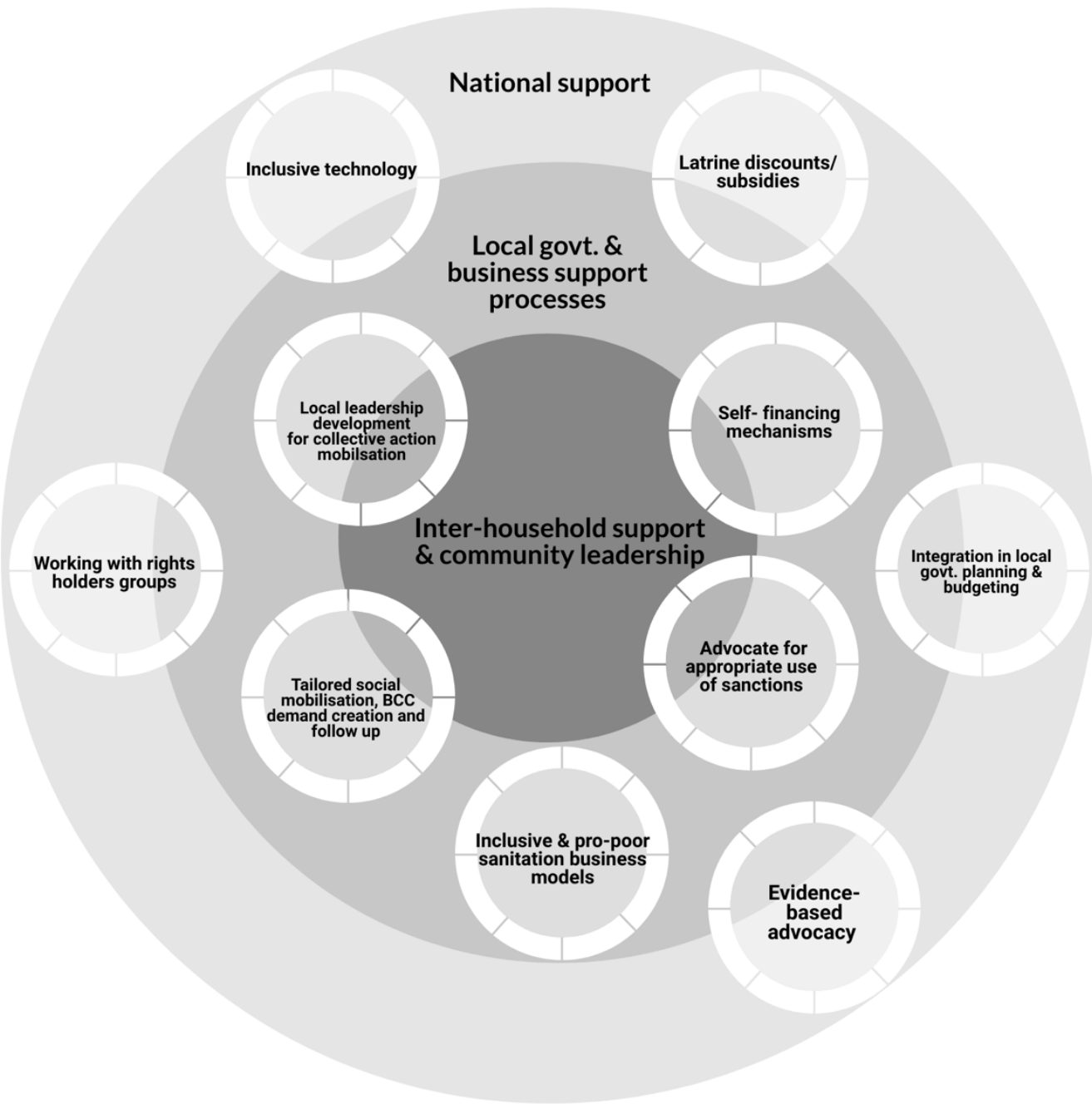

Figure 1: Locating SSH4A support strategies across different scales

\section{Defining success and strengthening evidence}

Finally, there is a need to build evidence about the success or otherwise of inclusive sanitation initiatives by better tracking attributable outcomes associated with different support strategies. This requires two critical components. First, it requires a clearly articulated conception of success. Success of the support mechanisms is often interpreted amongst rural sanitation programmes in terms of the numbers of vulnerable groups or households that have gained access to improved facilities, but a more nuanced conception of success is beneficial. Building on collective wisdom and experiences from a decade of SSH4A programming, SNV is developing a conception of success around five tenets: (i) everyone, including disadvantaged individuals and groups, should gain access to suitable sanitation facilities that are acceptable, used and sustained over time; (ii) mechanisms to increase sanitation access in one area must not inadvertently hinder progress in other areas; (iii) mechanisms must avoid creating perverse incentives that undermine sanitation governance systems or inhibit the development of sanitation markets; (iv) the cost and complexity of any support mechanism should not be prohibitive to scaling; and (v) introduced support mechanisms should add value to existing support services and contribute to good governance.

With a clear conception of success in mind, inclusive sanitation programs must then articulate monitoring and evaluation approaches that allow meaningful consideration of the relative success or 
otherwise of different strategies, in different contexts, used at different points in time. Mapping strategies to their outcomes is critical to facilitate learning and adaptation, and is a gap in current sector knowledge. Continuing to invest in and innovate monitoring approaches is of the highest priority.

\section{Conclusion}

In order to achieve universal rural sanitation, there is a need for stronger evidence about practical strategies for reaching disadvantaged individuals and groups. In this paper we have presented analysis of the inclusion strategies used by SNV teams across five countries. These strategies reflect a broad conception of what 'support mechanisms' look like that draws on thinking from behavioural, market-oriented and financial rural sanitation approaches, as well as insights on strengthening local institutions. Findings point to the benefits of a toolbox approach to reaching all, with strategies adapted to best suit different contexts at different points in a program's evolution. The toolbox approach also reflects the multi-dimensional and intersectional nature of disadvantage recognising that people are not being left behind only due to a single reason such affordability, lack of access to markets, or behavioural norms.

The analysis reinforces the pivotal role of local government in reaching all both within and beyond a program timeframe. Local government is both primarily responsible for ensuring services reach all, and well placed to drive systemic changes towards greater inclusion. Implementation of support mechanisms therefore requires strong involvement from local government to both strengthen institutional capacity for inclusive service delivery, and to establish systems for ensuring the sustainability of mechanisms put in place.

Finally, our analysis identifies opportunities for rural sanitation programs to more clearly articulate a comprehensive conceptualisation of success in reaching all, which encompasses both the practicalities of services as well as impacts on wider governance and market dynamics. This can form the basis for sound monitoring and evaluation that enables reflection on the effectiveness of various strategies in achieving intended (and unintended) outcomes, their scalability and their sustainability. With a decade to achieve the ambitious agenda established by the SDGs, more work is needed to identify who is being left behind, tailor strategies to meet their needs, determine the optimal timing for introducing support mechanisms, and to monitor and document the relative effectiveness of strategies in reaching different groups. This work will help to create the critical mass of evidence needed to drive a successful global push toward universal sanitation.

\section{Acknowledgements}

The authors gratefully acknowledge the contributions and reviews provided by SNV team members Nadira Khawaja, Antoinette Kome; Sunetra Lala, Anne Mutta, Kumbulani Ndlovu, Jackson Wandera and Kencho Wangdi. This research was jointly supported by the Australian Government through the Department of Foreign Affairs and Trade (DFAT) and SNV. Sustainable Sanitation and Hygiene for All is a multi-donor programme funded by the UK Department of Foreign Affairs and International Development (DFID) in Zambia, Tanzania and Nepal, by the Australian Government in Nepal and Bhutan, the Stone Family Foundation in Cambodia and the Embassies of the Kingdom of the Netherlands.

\section{References}

Ahmed, S., H. Jahan, B. Bala, and M. Hall. 2011., "Inclusive Sanitation: Breaking Down Barriers." Paper presented at the 35th WEDC International Conference, Loughborough, July 6-8. https://wedcknowledge.lboro.ac.uk/resources/conference/35/Ahmed-S-1132.pdf. 
Bateman, M. and S. Engel. 2018. "To shame or not to shame - that is the sanitation question." Development Policy Review, 36(2): 155-173.

Carrard, N.R., J. Crawford, G. Halcrow, C. Rowland, and J.R. Willetts. 2013., "A framework for exploring gender equality outcomes from WASH programs." Waterlines: international journal of water, sanitation and waste, 32(4): 315-333.

Cavill, S., S. Roose, C. Stephen, and J. Wilbur. 2016. "Putting the hardest to reach at the heart of the Sustainable Development Goals." In Sustainable Sanitation for All, edited by P. Bongartz, N. Vernon, and J. Fox. Rugby: Practical Action Publishing.

de Albuquerque, C. 2014. Realising the human rights to water and sanitation- $A$ handbook by the UN Special Rapporteur Catarina de Albuquerque. UN Special Rapporteur on the human right to safe drinking water and sanitation. Portugal.

Devine J., and C. Kullmann. 2011. Introductory guide to sanitation marketing. Washington DC: World Bank.

Engel, S., and A. Susilo. 2014. "Shaming and Sanitation in Indonesia: A Return to Colonial Public Health Practices?" Development and Change 45 (1): 157-178. doi:10.1111/dech.12075.

Evans, B., C. van der Voorden, and A. Peal. 2009. Public Funding for Sanitation - The Many Faces of Sanitation Subsidies. Switzerland: Water Supply \& Sanitation Collaborative Council.

Garn, J., P. A. Apanga, and M. C. Freeman. 2018. "Beyond the Finish Line: patterns of progress and equity in rural sanitation." Paper presented at World Water Week, Stockholm, August 26-31. http://www.snv.org/public/cms/sites/default/files/explore/download/emory-presentation.pdf.

Gero, A., N. Carrard, J. Murta, \& J. Willetts. 2013. Private and social enterprise engagement in water and sanitation for the poor: A systematic review of current evidence. Australia: Institute for Sustainable Futures, University of Technology.

House, S., S. Cavill, and S. Ferron. 2017. "Equality and non-discrimination (EQND) in sanitation programmes at scale." Frontiers of CLTS 10: Part 1 of 2: Innovations and Insights, Brighton: IDS.

House, S., S. Ferron, and S. Cavill. 2017. "Scoping and Diagnosis of the Global Sanitation Fund's Approach to Equality and Non-Discrimination." Switzerland: Water Supply \& Sanitation Collaborative Council.

IDinsight. 2013. "Microfinance loans to increase sanitary latrine sales, Evidence from a randomized trial in rural Cambodia." http://www.lboro.ac.uk/well/resources/fact-sheets/fact-sheets$\mathrm{htm} / \mathrm{mcfs} . \mathrm{htm}$

ISF-UTS and SNV. 2018. Sanitation for all: A comparative study of approaches to leaving no one behind across five countries. Prepared for SNV Sustainable Sanitation and Hygiene for All (SSH4A) Programme. https://www.uts.edu.au/sites/default/files/article/downloads/SNV\%20ISF_San4All_ACmprativ Study 2018\%5B1\%5D.pdf

ISF-UTS. 2016. Learning Brief 4: Driving Equality, Enterprise in WASH, Prepared by the Institute for Sustainable Futures, University of Technology Sydney. www.enterpriseinwash.info.

Jenkins, M.W. and B. Scott. 2007. "Behavioral indicators of household decision-making and demand for sanitation and potential gains from social marketing in Ghana." Social Science \& Medicine 64(12): 2427-2442. 
Jenkins, M. W., and S Sugden. 2006. Rethinking Sanitation: Lessons and Innovation for Sustainability and Success in the New Millennium. London.

Keatman, T., L. Gosling, N. Carrard, H. Neumeyer, J. Murta, V. Roaf and A. Adam. 2016. "Achieving universal and equitable access to water, sanitation and hygiene (WASH) for all practitioner perspectives and perceptions." Paper presented at RWSN, Proceedings of the 7th RWSN Forum "Water for All”, Abidjan, November 29 - December 2. DOI: 10.13140/RG.2.2.23154.50880

Kohlitz, J., N. Carrard and J. Willetts. 2019. "Support mechanisms to strengthen equality and nondiscrimination (EQND) in rural sanitation" Frontiers of CLTS 13: Part 2 of 2: Innovations and Insights, Brighton: IDS.

Kwolek, M. 2012. "Sanitation finance: Access to Capital for Entrepreneurs and End-Users." Water for People.

Leahy, C., J. Lunel, M. Grant, and J. Willetts. 2017. "Women in WASH Enterprises: Learning from female entrepreneurship in Cambodia, Indonesia and Lao PDR" Enterprise in WASH - Working Paper 6. Australia: Institute for Sustainable Futures, University of Technology Sydney.

Molyneux, M., 1985. Mobilization without Emancipation? Women's Interests, the State, and Revolution in Nicaragua. Fem. Stud. 11, 227-254. https://doi.org/10.2307/3177922

Moser, C.O.N., 1989. Gender planning in the third world: Meeting practical and strategic gender needs. World Dev. 17, 1799-1825. https://doi.org/10.1016/0305-750X(89)90201-5.

Murta, J., T. Foster, and J.R. Willetts. 2017. Review of SNV's Pro-poor support mechanism in Banteay Meas district, Cambodia. Report prepared by the Institute for Sustainable Futures, University of Technology Sydney for SNV.

Myers, J., L. Maule, M. Gnilo, R. Chambers, and S. Cavill. 2017., Supporting the Least Able Throughout and Beyond CLTS. CLTS Knowledge Hub, Learning Brief.

Nilsson, M., D. Griggs, and M. Visbeck. 2016. "Map the interactions between sustainable development goal." Nature 534: 320-322.

Pati, B.K. and H. Neumayer. 2018. "Making rights real in India: using a tool on the rights to water and sanitaion with local government officials." Paper presented at the $41^{\text {st }}$ WEDC International Conference, Nakuru, 2014.

Robinson, A., and M. Gnilo. 2016. "Beyond ODF: A Phased Approach to Rural Sanitation Development." In Sustainable Sanitation for All, edited by Petra Bongartz, Naomi Vernon, and John Fox. Rugby: Practical Action Publishing.

Robinson, A. and M. Gnilo. 2016b. "Promoting choice: smart finance for rural sanitation development", in Sustainable Sanitation for All: Experiences, Challenges, and Innovations, edited by P. Bongartz, N. Vernon and J. Fox. Rugby: Practical Action Publishing.

Rosenqvist, T., C. Mitchell, and J.R Willetts. 2016. "A Short History of How We Think and Talk about Sanitation Services and Why It Matters." Journal of Water, Sanitation and Hygiene for Development 6 (2): 298-312. doi:10.2166/washdev.2016.118.

Slaymaker, T., 2019. "Leave no one behind: progressively reducing inequalities in drinking water, 
sanitation and hygiene", data from WHO/UNICEF Joint Monitoring Programme for Water Supply, Sanitation and Hygiene presented at Water for Women Fund World Water Day Joint Celebration: Leave no one behind Bangkok 22nd March, 2019. Accessed 20 May 2019.

https://rive.google.com/file/d/15X1564gTkdSgupn1 togUwPofEheHjaVX/view.

SNV, 2019. SNV's approach to 'Do No Harm': Bhutan [Practice Brief]. The Hague: SNV.

Triwahyudi, W. and E. Setiawan. 2014. "Disability inclusion in WASH: "What has been achieved and how can this help other practitioners?" Paper presented at the $37^{\text {th }}$ WEDC International Conference, Hanoi, 2014.

UN. 2015. "Goal 6: Ensure access to water and sanitation for all." Sustainable Development Goals (SDGs). Accessed 15 April 2019. https://www.un.org/sustainabledevelopment/water-andsanitation/

UN-Water. 2017. Eliminating discrimination and inequalities in access to water and sanitation. Switzerland: UN-Water Technical Advisory Unit.

Venkataramanan, V. 2016. CLTS Learning Series: Lessons from CLTS Implementation in Seven Countries. Chapel Hill, USA: The Water Institute at UNC.

Venkataramanan, V. 2017. Review of rural sanitation approaches. Chapel Hill, USA: The Water Institute at UNC.

Wei, Y., A. May and R. Chowdhury. 2016. "Instituting equity and inclusion in market-based approaches: reaching the poor and disabled in sanitation." Paper presented at the $39^{\text {th }}$ WEDC International Conference, Kumasi, 2016.

WHO and UNICEF. 2019. Progress on household drinking water, sanitation and hygiene 20002017. Special focus on inequalities. Geneva: World Health Organization (WHO) and the United Nations Children's Fun (UNICEF).

Willetts, J., Gero, A., Susamto, A., Sanjaya, R. Thanh Doan Trieu, Murta, J. and Carrard, N. 2017. "Sanitation value chains in low density settings in Indonesia and Vietnam: impetus for a rethink to achieve pro-poor outcomes". Journal of Water, Sanitation and Hygiene for Development, 7(3): 445- 454. doi.org/10.2166/washdev.2017.141.

Willetts, J.R., J. Murta, A. Gero, N. Carrard, and D. Harris. 2015. "Political economy influences on enterprise engagement in Indonesia, Vietnam and Timor-Leste." Paper presented at WASH Services Beyond 2015: Improving Access and Sustainability, the 38th WEDC Conference, Loughborough, July 27-31.

Willetts, J.R. and B. Powell. 2016. Financing Sanitation: Finding a Middle Path to Reach the Poor. Brisbane. http://www.cswashfund.org/sites/default/files/LearningBrief_Financing sanitation_FINAL_0.pdf.

Willetts, J.R (2013), Supporting the poor to access sanitation in Bokeo province, Laos. Prepared by Institute for Sustainable Futures, University of Technology Sydney for Plan Laos and Plan Australia, June 2013. 


\section{Author biographies}

Naomi Carrard is an applied researcher and passionate advocate for safe, sustainable water, sanitation and hygiene (WASH). She has qualifications in Environmental Law and Geography, and more than fifteen years' experience working in WASH, water resource management and development effectiveness across Asia and Pacific countries. Naomi has particular expertise in the WASH-gender nexus, the human rights to water and sanitation, and integration of WASH with planetary boundary considerations.

Jeremy Kohlitz is a WASH researcher with special interest in Pacific island countries and territories and the wider Asia region. His primary areas of expertise include interdisciplinary and applied research on sustainability of rural water, rural sanitation, and urban sanitation services, and climate change impacts on WASH services.

Simone Soeters is a practitioner, advisor and research with a primary focus on the sub-Saharan and South East Asian regions. Her research has a strong focus on gender and equity, building on previous experience in the areas of health system strengthening, community based approaches to development, and monitoring, evaluation and learning.

Gabrielle Halcrow is SNVs Programme Coordinator for the Sustainable Sanitation and Hygiene for All (rural) Programme in Asia. She has a technical background in international and environmental health with twenty years of professional experience working with WASH, gender equality and public health programmes with local and state governments and international development organisations.

Janina Murta has qualifications in Environmental Engineering and Integrated Water Management, and more than ten years' experience working in environmental protection, social justice and community development.

Juliet Willetts leads applied research to improve development policy and practice and to address social justice and sustainable development. She is a recognised expert in the field of water and sanitation in developing country contexts, and also works on issues related to gender equality, civil society role in development, governance and accountability, climate change, urban development, monitoring, evaluation and development effectiveness more broadly. 